\title{
Editorial
}

\section{Diet, cancer and public health nutrition}

The World Cancer Research Fund (WCRF) estimates approximately 11.3 million new cancer cases and 7.9 million deaths in 2007 worldwide. These figures are projected to rise to 15.5 million new cases and 11.5 million deaths in $2030^{(1)}$. While population growth and ageing will in part drive this increase, social and economic changes will bring about increases in diet-related cancers as well ${ }^{(2)}$, as has been the case in China ${ }^{(3)}$

Is the diet-and-cancer research community poised to handle the oncoming cancer burden? In this era of individualized medicine and personalized nutrition, interest in nutritional genomics, metabolomics and proteomics naturally continues to thrive, as does the search for chemopreventive agents. But public health prevention occurs at the population level. And while the individualization of nutrition continues, work in public health nutrition should continue to expand in the other direction.

What form should these efforts take? Many of the major diet-related causes of cancer are already known with some degree of confidence. Aflatoxins are recognized risk factors for liver cancer, as are salt and salt-preserved foods for stomach cancer ${ }^{(4)}$. Insufficient fruit and vegetable intake is thought to account for 374000 cancer deaths worldwide; alcohol is the likely culprit in 351000 cancer deaths; and 139000 cancer deaths have been attributed to overweight and obesity ${ }^{(5)}$. Much of what we need to know to eat well we already know, and this has been summarized, with sources of evidence documented in fine, comprehensive detail, by the $\mathrm{WCRF}^{(4)}$. And yet research on diet and cancer continues, because clearly this knowledge isn't enough.

I suggest three areas for our work to fit the times and to advance the current state of our knowledge. I welcome comments or suggestions from others. The first area falls into the more traditional realm of nutritional epidemiology identification of biomarkers. Long latency makes cancer a difficult outcome in epidemiological studies; this is true for aetiological observations, but even more so for intervention trials. Continued efforts to understand the disease process and to identify relevant biomarkers are crucial for any evaluation of nutrition-related predictors and cancer risk.

A second sort of research we need falls more on the 'public health' than on the 'nutrition' side of public health nutrition - studies demonstrating associations of community or societal characteristics, such as the food environment, pricing policies and food safety regulation, with cancer-related outcomes, or comparing the effectiveness of different policies. Ultimately, we need fewer recommendations to increase consumption of berries, but more concrete recommendations on policies that make berries (or fruit, more generally) more available and affordable; fewer recommendations to decrease fat intake (a lesson learned the hard way ${ }^{(6)}$ ), and more recommendations on incentives to change agricultural policies that artificially suppress the true cost of producing industrial beef and pork. The WCRF report on Policy and Action for Cancer Prevention ${ }^{(1)}$, reviewed in the current issue of Public Health Nutrition ${ }^{(7)}$, lies right at the intersection of diet, cancer and public health nutrition and is a sound stepping-off point for pursuing more distal, 'underlying and basic causes' of cancer in our work.

Finally, we should strive to change people's unrealistic expectations of food. For decades, our research has given the impression that indulging in a bit of dark chocolate or cooking with garlic are effective strategies for reducing cancer risk. Rather than being viewed as aetiological or even chemopreventive agents, they have been taken as personal recommendations for dietary change. This has been an enormous disservice. While we ourselves may understand the limits and implications of our findings, the lay community interprets our work differently. It is time to change these impressions by de-emphasizing our focus on nutrients and foods, or at least by stating explicitly that these are not meant to form the basis of cancer prevention strategies, and by doing research that communicates what it means to eat well. In the USA, for example, we might study whether eating well means only having a green salad for lunch every day and sweets just on special occasions; whether a sitdown steak-and-potatoes dinner is equivalent to a fast-food hamburger-and-fries meal; or whether a beef-and-potato kind of diet is the same health-wise when consumed alone while driving as opposed to eaten at the dinner table with family. In places where people still have some cultural sense about what it means to eat well, research might look at different aspects of traditional ways of eating to identify what works - and then encourage people to hold on to those traditions in the face of social and economic change.

Important details are still being filled in, but much of what we need to know about what to eat to prevent cancer we already know. What we don't know enough about is how to actually go ahead and do it - to eat well and, through our research or practice, to help others eat well. The research that will move us forward will provide the resources we need to get us - 'us' meaning governing bodies, academics and health professionals, workplaces and schools, parents, ourselves - to go ahead and do it.

Marilyn Tseng Deputy Editor 


\section{References}

1. World Cancer Research Fund/American Institute for Cancer Research (2009) Policy and Action for Cancer Prevention. Food, Nutrition, and Physical Activity: A Global Perspective. Washington, DC: AICR.

2. Boyle P \& Levin B (editors) (2008) World Cancer Report 2008. Lyon: International Agency for Research on Cancer.

3. Chen JG, Zhu J, Parkin DM, Zhang YH, Lu JH, Zhu YR \& Chen TY (2006) Trends in the incidence of cancer in Qidong, China, 1978-2002. Int J Cancer 119, 1447-1454.

Public Health Nutrition: 12(6), 738

\section{In this issue}

Food and beverages containing pharmacologically active substances are consumed in many food cultures worldwide. This is often a consequence of the fact that the plants we eat not only contain nutrients but also have evolved to produce compounds that serve to assist the plant survive in an environment thick with herbivores. Coffee beans and the betel-nut are two of the most commonly consumed examples of plant-derived foodstuff that have effects that are more neurological than nutritional, with both widely suspected of having independent effects on health outcomes. In this issue, Fuhrman et al. ${ }^{(1)}$ focus on the risk of incident diabetes associated with coffee intake in Puerto Rican men, with data suggesting a protective effect of coffee consumption.

In these times of global financial crisis, the paper by Darmon et $a l^{(2)}$ that compares low-cost foods with brand-name equivalents in France is particularly relevant. While the authors acknowledge the difficulties in analysing the relationship between cost and quality of foodstuffs because of a lack of mandatory food labelling, their analysis does suggest that diverting consumers away from low-cost food options to more expensive brandnamed foods is not justified on nutritional grounds.

Infants and children are particularly vulnerable to suboptimal nutrition and as a result are a common focus for nutrition research. Three papers in this issue focus on nutrition and growth-related issues amongst infants and children. Janjua et $a l^{(3)}$ explore the determinants of low birth weight in urban Pakistan, Fausto et al. ${ }^{(4)}$ evaluate growth parameters of infants born to HIV-1-infected mothers in Brazil and Gera et $a l^{(5)}$ report on a systematic review of the effect of combining multiple micronutrients with Fe supplements.

There has been a surge in the scrutiny applied to food industry advertising by the nutrition community, particularly that targeting children as a vulnerable group, with a number of studies already published in this journal in
4. World Cancer Research Fund/American Institute for Cancer Research (2007) Food, Nutrition, Physical Activity, and the Prevention of Cancer: A Global Perspective. Washington, DC: AICR.

5. Danaei G, Vander Hoorn S, Lopez AD, Murray CJ \& Ezzati M (2005) Causes of cancer in the world: comparative risk assessment of nine behavioural and environmental risk factors. Lancet 366, 1784-1793.

6. Taubes G (2002) What if it's all been a big fat lie? The New York Times Magazine, 7 July.

7. Swinburn B (2009) Prevention of cancer. A colossal achievement, with much more to do. Public Health Nutr 12, 877-878.

doi:10.1017/S1368980009005771

past issues. Morgan et al. ${ }^{(6)}$ add to this debate in this issue via a paper that analyses British commercial television advertising of foods targeting children, with specific reference to oral health. Their findings suggest that there has been a shift away from advertising of confectionery to foods that might be considered healthier but contain large amounts of hidden sugar. This implies that scrutiny does lead to change in advertising practices, but not necessarily change resulting in the promotion of healthier food to children. It appears that further scrutiny is required, if not legislation.

Roger Hughes Deputy Editor

\section{References}

1. Fuhrman BJ, Smit E, Crespo CJ \& Garcia-Palmieri MR (2009) Coffee intake and risk of incident diabetes in Puerto Rican men: results from the Puerto Rico Heart Health Program. Public Health Nutr 12, 842-848.

2. Darmon N, Caillavet F, Joly C, Maillot M \& Drewnowski A (2009) Low-cost foods: how do they compare with their brand name equivalents? A French study. Public Health Nutr 12, 808-815.

3. Janjua NZ, Delzell E, Larson RR, Meleth S, Kristensen S, Kabagambe E \& Sathiakumar N (2009) Determinants of low birth weight in urban Pakistan. Public Health Nutr 12, 789-798.

4. Fausto MA, Carneiro M, Antunes CMF, Colosimo EA \& Pinto JA (2009) Longitudinal growth of infants born to HIV-1infected mothers in Belo Horizonte, Brazil. Public Health Nutr 12, 783-788.

5. Gera T, Sachdev HPS \& Nestel P (2009) Effect of combining multiple micronutrients with iron supplementation on $\mathrm{Hb}$ response in children: systematic review of randomized controlled trials. Public Health Nutr 12, 756-773.

6. Morgan M, Fairchild R, Phillips A, Stewart K \& Hunter L (2009) A content analysis of children's television advertising: focus on food and oral health. Public Health Nutr $\mathbf{1 2}$, 748-755. 